\title{
Academic Library Reserves, Photocopying, and the Copyright Law
}

by John C. Stedman

Editor's note: John C. Stedman is emeritus professor of law, University of Wisconsin-Madison, and chair of the AAUP Committee on Copyright Law. This article appears in a slightly modified form in AAUP Bulletin 64:142-49 (September 1978).

\section{INTRODUCTION}

The number of questions librarians have about the new copyright legislation and its application to library operations is exceeded only by the amount of information available about the new law. Answers to questions are not easily obtained, and librarians have become increasingly wary of advocacy documents such as the Association of American Publishers' recently published Photocopying by Academic, Public and Nonprofit Research Libraries and its earlier Photocopying by Corporate Libraries. Although both of these documents purport to be explanatory of the Copyright Act of 1976 as it applies to libraries, they contain many misrepresentations and offer misleading guidance to librarians.

Because of the importance of the topic to academic librarians and the need for objective analysis, $C$ \& $R L$ News has published several articles on copyright and reserve operations during the past months. This most recent addition to the literature, written by John C. Stedman, an emeritus professor of law at the University of Wisconsin-Madison, sheds some additional light on several complex reserve-copyright issues. Professor Stedman's reasonable and objective discussions of sections 108 and 107 and the Guidelines for Classroom Copying should assist librarians in interpreting copyright legislation. Armed with this article and the material issued in the American Library Association's Librarian's Copyright Kit, librarians should have little difficulty in finding answers to many of their copyright questions.-Meredith A. Butler, Chair, ACRL Copyright Committee.

Does the common, and academically important, practice of photocopying copyrighted materials and putting them on "reserve" for usage by students constitute copyright infringement? The attention this question has received is exceeded only by the inconclusiveness of the answers.

(C) 1978, American Association of University Professors
Some commentators are sure that it constitutes infringement; others are equally sure that it does not. The following comments attempt to search out the line between permissible and impermissible photocopying for such purposes and to spell out the considerations that suggest permissibility in most instances.

"Reserves," for purposes of this discussion, are defined as selected writings made available to individual and successive students for educational purposes, subject to sharp time limitations and usually, restrictions on physical removal from the library premises. The copyright issue does not arise except with respect to copyrighted materials that have been copied without the express or implied consent of the copyright owner. Nor is the present discussion concerned with libraries that are connected with commercial organizations, or the possible liability of persons other than the libraries or teacher-for instance, students-who engage in unauthorized photocopying on unsupervised copying machines (see section 108[f]). In short, we are concerned here only with the teacher-or the library acting upon the teacher's request or on its own initiative-who makes, or has made, the unauthorized copies in question and who places them on reserve.

Since such practice involves a "copying" within the meaning of the copyright law, it constitutes infringement (see section 106[1]) unless such use is permitted by section 107 or $108 .^{1}$

\section{Section 108 - Library Photocopying}

It is logical (if not chronological) to start with section 108 rather than 107 , since it is the narrower and more specific of the two. The structure of section 108 is quite complex. Subsections (b) through (e) set out the circumstances in which photocopying is permitted, namely, for purposes of preservation or restoration (subsections [b] and [c]) or to comply with the request of a user (subsections [d] and [e]). Subsections (b) and (c) are not relevant to the present discussion, but subsections (d) and (e) are. Subsection (d) permits a library, at the request of a user, to provide a copy from its or another library's collection "of no more than one article or other contribution to a copyrighted collection or periodical issue, or of a small part of any other copyrighted work," provided (1) the copy becomes the property of the user, (2) the library has no notice that it is to be used "for any purpose other than private study, scholarship, or research," and (3) the library displays or includes a "warning of copyright." Subsection (e) permits a library to 
provide a copy of an "entire work or . . . a substantial part of it," subject to the same conditions plus the added condition that the library "has first determined ... that a copy . . . cannot be obtained at a fair price."

In addition to the above limitations, subsections (d) and (e) are also subject to four important general limitations set forth in subsection (a), namely, that (1) the library make "no more than one copy" (although it may repeat "on separate occasions" provided the repetitions are "isolated and unrelated"-subsection [g]); (2) the copying is done "without any purpose of direct or indirect commercial advantage"; (3) its collections are available to the public or researchers; and (4) a notice of copyright is included.

As the foregoing indicates, the conditions to be met are numerous and technical, but compliance with them in meeting the needs of individual students should cause no serious problem. The closer question, especially in view of the "one copy" limitation, is their applicability to-or perhaps, their practicability in-the "reserve" situation. Under section 108(d), an individual student could request a copy of a referenced article. But could more than one student request a copy of the article? Could a student who legally obtained a copy through this procedure share it with others? The potentialities of these as alternatives to the traditional "reserve" system are obvious-and it is a little hard to see why a result that could be achieved by these indirect and inefficient methods, if they are permissible, should not be achievable by the simpler and more efficient method of simply putting a limited number of copies on reserve.

The premise of noninfringement runs into difficulty, however, in the face of section 108 language.

(I) Suppose the recipient turns the copy over to others, either on loan or irrevocably? In that case, does it meet the requirement of "pricate study, scholarship, or research"? It would seem that it does; and even if it does not, the library should be free of liability if it had no notice of the recipient's intent to pass on the copy (see subsections (d) and (e)). But one cannot be sure. The answer may be "yes" or "no" depending on who is interpreting the statutes. ${ }^{2}$

(2) If more than one request is filled, might the library be in violation of subsection (g), which provides that the rights to make additional copies on separate occasions "do not extend to cases where the library. . . is aware or has substantial reason to believe that it is engaging in the related or concerted reproduction or distribution of multiple copies ... whether made on one occasion or over a period of time, and whether intended for aggregate use by one or more individuals or for separate use by the individual members of a group"?

The murkiness of this language defies interpre- tation at any level short of judicial omniscience. ${ }^{3}$ Nevertheless, at some point along the road of repeated photocopying in these circumstances it seems inevitable that a court would conclude that the library was, or should have been, "aware." Up to that point, however, the library would be home free.

About the most one can say regarding section 108 is that a library, acting in good faith, could fill a single student's (or teacher's) request for a single copy, but beyond that would move increasingly into deeper water as repeated reproductions occurred. All in all, section 108 provides a possible means of meeting students' needs, but the means are limited. It is a road pockmarked with pitfalls.

\section{Section 107-Fair Use}

Section 107, in contrast, offers greater possibilities. One must explore this section from two standpoints: (1) the language of the statute itself and (2) the gloss (a somewhat tarnished gloss) that has been put upon it by the highly publicized (and often distorted and misinterpreted) Guidelines for Classroom Copying agreed upon by the Ad Hoc Committee of Educational Institutions, the Authors League of America, and the Association of American Publishers.

Section 107, standing alone, seems to provide considerable freedom to educational photocopiers-granted that its rather vague and general language will engender considerable uncertainty until the courts have authoritatively spoken. The section codifies an equitable doctrine that has been an unwritten part of the copyright law for more than a hundred years. Traditionally its application has been largely restricted to the use of excerpts as part of further writings, ${ }^{5}$ but the Congress that enacted the Copyright Law of 1976 went further. It clearly viewed section 107 as, among other things, a means of balancing the respective interests of the copyright owner and the user of copyrighted materials. As the House Report puts it, "it is the intent of this legislation to provide an appropriate balancing of the rights of creators, and the needs of users. "6

Section 107 prescribes four factors to be considered in determining whether a use is "fair": (1) purpose and character of the use, (2) nature of the work, (3) amount and substantiality of the portion used, and (4) effect upon the market for the work. Of these four, it is the last-the effect upon the owner's market-that is likely to be given the most weight. For reasons indicated later, this consideration may well strengthen the position of one claiming freedom to photocopy for reserve purposes. A second consideration operating in one's favor is the twice-expressed reference in the section to educational usage. It (1) defines "fair use" as including "purposes such as ... teaching (including multiple copies for classroom use), scholarship, or research," and (2) refers to 
"the purpose and character of the use" as "including whether such use is of a commercial nature or is for nonprofit and educational purposes."

These provisions should give considerable aid and comfort to the would-be "reserve" copyist. Within the area under discussion, "reserve" photocopying incontrovertibly qualifies as being "for nonprofit educational purposes." Furthermore, if it is permissible to make "multiple copies for classroom use," it would seem to follow logically that one could make a smaller number for use under the restrictive conditions that typically apply to a library reserve program.

But what about the effect upon the market? The strong opposition of coyright owners to reserve practices apparently stems from the fear that such practices will seriously undercut their sales. As the Register of Copyrights has observed, "This practice was used as kind of a monster, an example of things that shouldn't be done." Are these fears well founded? If entire books or a substantial part thereof are photocopied, they may well be. If access to the material is important enough to warrant photocopying this extensively, the institution would probably, although not necessarily, ${ }^{8}$ purchase a copy rather than do without. But it is also true that, in the absence of unusual circumstances such as outrageous price, inaccessibility, or long delay in obtaining the copy, the institution would probably purchase rather than photocopy, anyway. All in all, the cases in which book-length materials are photocopied for reserve purposes are likely to be rare, and the situations in which such practices will deprive the copyright owner of a sale even more rare. Such statistical studies as have been made bear this out. ${ }^{8}$

The photocopying of a single chapter or excerpt, or of a single article from a periodical, involves different considerations. Here the reserve photocopying practice is much more common. At the same time, however, it is much less likely to cut into sales. Everything else being equal, the single chapter or article generally plays a less essential role in the ongoing educational process than does the book-length treatise. A given copy, being shorter and therefore subject to more rapid turnover, will normally serve more students, thus reducing the number needed for reserve. The student who desires a copy for personal use (or to pass around to others) will be more inclined to run off one undetected on an unsupervised machine than to buy a copy. Authorized purchased copies are less likely to be available promptly and at a reasonable price. ${ }^{10}$ Often the material wanted is not available at all unless one is willing to buy the larger publication in which it is contained (shades of the antitrust law ban on tie-ins!). Even if permission is given to copy articles, the charge imposed by many publishers (including nonprofit publishers) may far exceed what could be deemed, by any test, a reasonable price (conceivably to induce one to purchase instead of to photocopy) ${ }^{11}$-and in excess of what the nonprofit educational institution is able or willing to pay for the privilege.

Taking everything into consideration, one may suggest the following conclusions with respect to section 107

1. An educational institution will not normally photocopy, for reserve purposes, materials that it can more economically obtain by purchase.

2. As a consequence, it will purchase, rather than photocopy, materials of a voluminous nature such as books, provided they are obtainable promptly and on reasonable terms.

3. If denied permission to photocopy shorter materials (articles, excerpts, chapters, etc.), it will be unlikely to purchase additional copies, unless obtainable promptly and on clearly reasonable terms, but instead will make and distribute multiple copies for classroom use to the extent permissible or, except for copies already owned, forgo use of the material in question. Whatever alternative it adopts, the probability of any additional remuneration of significance to the copyright owners is slight.

4. This being so, a balancing of the burdens upon users (in terms, not only of financial costs, but also of uncertainty, delay, and non-use) of denying the right to engage in reserve photocopying, against the minuscule benefits likely to accrue to copyright owners, supports a conclusion

\section{Our Success was Achieved by Putting Your} Success First

We know our future depends on your satisfaction with our service. Since 1962 the highest standards in completion of orders, actual publisher reports (not our stock status), and accurate invoicing to your requirements places us as the best order source for many acquisition librarians.

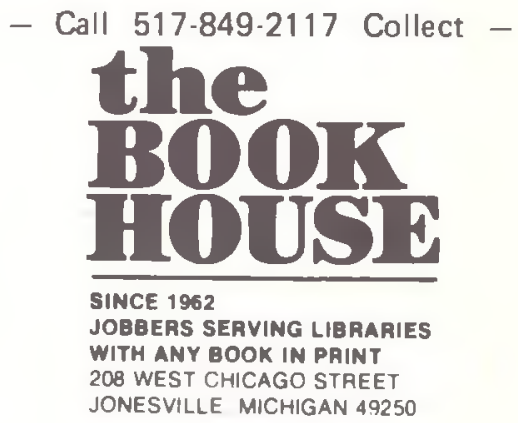


that reserve copying, within reason, should be deemed a "fair use" under section 107.

What constitutes a use "within reason" is difficult to define, and the language of section 107 gives no guidance in this respect except for the general factors previously mentioned. To a large extent the problem should resolve itself, since libraries, in the exercise of good judgment, are unlikely to photocopy if the material they want is available from authorized sources promptly, in adequate form and supply, and at a reasonable price-photocopying, after all, is not an inexpensive process. Irrespective of these considerations, if the copied materials come within the "fair use" test applied pursuant to the "multiple copies for classroom use" provision or meet the criteria of sections 108(d) and (e), discussed above, such uses should be deemed "reasonable" for reserve purposes, both because this conclusion conforms to the basic thinking of the Congress as expressed in sections 107 and 108 (since injury to copyright owners would probably be minimal) and because a contrary holding would pose serious enforcement problems - a result that courts are unlikely to view with much enthusiasm.

\section{Guidelines for Classhoom Copying}

There remains the question of the Guidelines for Classroom Copying. Some might dismiss them as inapplicable to reserve practices, since they are clearly directed, and limited, to classroom activities. Inevitably, however, they will bear upon the subject of reserves for several reasons: (1) they do deal with the same materials and with practices that have the same objectives as the reserve practices; (2) their criteria as to what practices should be acceptable under the "fair use" doctrine were agreed upon between the copyright owners and representatives of a substantial segment of educational users-an agreement that Congress knew of and found acceptable prior to final enactment of the Copyright Law; (3) guideline interpretations of what may be done under the "multiple copies for classroom use" provision may well affect conclusions as to what is reasonable "reserve" activity.

The Classroom Guidelines and their pros and cons have been extensively discussed elsewhere. Hence, there is no need to discuss them here except as they bear upon the "reserves" issue. Five points should be emphasized at the outset, however.

1). They set forth only minimum rules, i.e., what teachers can do with impunity. Despite some rather misleading terminology in spots, they do not, in terms, limit what a teacher can do under the law. In other words, practices not expressly authorized by the agreement may still constitute "fair use" under the general criteria set forth in section 107

2). Such commitments as may be contained in the guidelines are binding only upon those who entered into the agreement, not upon others whether they be private parties, courts, or government officials. Courts are free, of course, to take them into consideration and to follow them if they see fit, just as private parties are free to do so (both with respect to practices that the guidelines permit and practices that they purport to prohibit). ${ }^{12}$

3). As noted above, the guidelines refer only to classroom usages and say nothing about reserves.

4). Although not limited in their phraseology to elementary and secondary schools, there are indications that these, rather than institutions of higher education, were what the drafters had in mind. ${ }^{13}$

5). Athough noting with approval the existence and terms of the guidelines, the Congress did not view them as an authoritative interpretation of section 107. As the House committee report puts it: "The Committee believes the guidelines are a reasonable interpretation of the minimum standards of fair use. Teachers will know that copying within the guidelines is fair use." 14

The foregoing considerations become crucial when one considers certain provisions of the guidelines relating to brevity, spontaneity, and cumulative effect-provisions that pose problems for the reserve photocopying practice

Brevity. As a condition of permissibility, the guidelines set limits on the number of words or illustrations that a copied document may contain. For instance, poetry excerpts are not to exceed 250 words; articles are not to exceed 2,500 words; charts, diagrams, etc., are limited to one per book or periodical issue, etc. Such limits may or may not be practicable for elementary and secondary schools, but they are obviously impracticable in many higher education situations. In such cases, teachers desiring to use lengthier materials in their classes or wishing to put them on reserve have three choices: (1) forgo use; (2) obtain permission; or (3) contend that more extensive use meets the more general "fair use" criteria contained in section 107, even though not within the permissible limits set in the guidelines-a contention that should be persuasive, for reasons previously suggested, to the extent that the photocopying is "within reason," taking all factors into consideration. ${ }^{15}$

Spontaneity. The guidelines require that the copying be "at the instance and inspiration of the individual teacher" and that the decision to use be so close to the time of use as to make it "unreasonable to expect a timely reply to a request for permission." In many instances it may be easy to meet these requirements, especially the requirements of "individual inspiration"-it is the teacher, after all, who usually decides what materials to hand out to students or put on reserve for their use. ${ }^{16}$ Compliance with the time element may be more difficult-teachers often follow the practice of assigning such materials in successive 
years, although one rarely knows at a given time of use whether he or she will be using the same material next time. In any event, contrary to the implications of the guidelines, failure to meet these requirements does not render section 107 inoperable. Existence of either or both of these conditions (teacher's initiative and pressure of time) will undoubtedly strengthen the teacher's case in a "fair use" controversy, but nothing in section 107 suggests that either of them is indispensable to a "fair use" finding. Nor do the congressional committee reports provide support for giving to "spontaneity" the impact suggested in the guidelines. True, the Senate report, adopting verbatim a 1967 comment in a House report, refers to "spontaneity" in the sense that the initiative must come from the teacher, not from higher or outside authority, but it includes no mention of a time factor in that discussion. ${ }^{17}$ The House committee comment is even more circumspect. It merely states that its earlier discussion (from which the above Senate comment stemmed) "still has value as an analysis of various aspects of the problem." 18 In short, as noted previously, compliance with the guidelines assures the teacher protection, but noncompliance may still be defended as a "fair use."

Cumulative effect. The guidelines contain rigid limitations on the frequency of classroom use. Affirmatively, they permit copying (1) "for only one course in the school," (2) not more than one article, two excerpts, or three items from the same collective work or periodical volume during one class term, and (3) no more than nine instances of "multiple copying for one course during one class term." Negatively, they state that copying "repeated with respect to the same item by the same teacher from term to term" is "prohibited." One may concede that repetitious use may, depending upon the circumstances, have an adverse effect upon the market for the copied material and consequently be a factor to consider in determining whether a use is "fair." 19 There is nothing, however, in either the provisions of section 107 or the committee reports to support the restrictive test set forth in the guidelines or to suggest that the "fair use" defense is not available to one who goes beyond these guideline limits in classroom use or, for reasons previously suggested, in reserve photocopying.

\section{Conclusions}

In the light of what has been said, the following comments are in order:

(1) One must, of course, abide by such rules and conform to such procedures as are clearly required by the new statutes and the rules and regulations developed thereunder. For instance, the inclusion by librarians of a copyright notice on materials, the posting of warnings on unsupervised machines and incorporation thereof on order forms, acting passively rather than as the initiator in photocopying for class use and reserves, and so on, may seem mere technicalities to a library staff, but compliance with such conditions can spell the difference between liability and nonliability.

(2) Care should be taken to avoid unreasonable and excessive photocopying. It is one thing to photocopy in the good-faith belief that it is permissible under the statutes. It is quite another to insist upon photocopying in utter disregard of the legitimate rights of copyright owners or to persist in practices that are clearly illegal or have authoritatively been declared to constitute infringement. Such conduct could result in the award of statutory damages (typically a much heavier penalty than the "actual damages" to which the good-faith educational violator is subjected). ${ }^{20}$ It might also generate in the judiciary an adverse attitude toward photocopying for educational purposes in general, to the long-range detriment of the educational community

(3) At the same time, a practice that appears reasonably within the language and spirit of the new law-more specifically, of sections 108 and especially 107 -and which is important in the furtherance of higher education may, and should, be pursued up to the point where such practice is authoritatively held to constitute infringement. To refrain from practices that can reasonably be deemed permissible is a disservice to the cause of education and runs the risk of setting a pattern of conduct that ultimately grows (or degenerates) into a legal interpretation of the law. At the other extreme, continued persistence in a practice after it has been authoritatively outlawed subjects the educational community to the unpleasant results described in the preceding paragraph. In the latter situation, the only viable alternative is either to try to get the law changed by judicial or legislative means (if one feels strongly about it) or to bow to the decision.

(4) Putting materials on reserve, for educational purposes and at the request of teachers, would seem to be in accord with the foregoing principles provided proper procedures (discussed above) and good judgment as to reasonable limits are observed. The variety in circumstances makes it impossible to lay down definite rules concerning what can and cannot be done-past efforts to do so underline the futility of this approach. As benchmarks to guide one in this inherently uncertain area, however, the following observations should prove useful: (1) If users and copyright owners, singly or in groups, can voluntarily agree upon a satisfactory arrangement-fine. One can only applaud such efforts. The problems arise not from this procedure, as such, but from private parties or groups that purport to speak for others who have not consented to such representation, or from the arrogation of such an agreement into a rule of law. (2) The Classroom Guidelines should be taken for what they are, namely, a vol- 
untary agreement as to minimum permissible practices, with the validity still to be determined under the general "fair use" doctrine set forth in section 107 as to practices that go further than those approved in the guidelines. (3) "Fair use" under section 107 is to be determined in light of the provisions relating to educational uses and by application of the four factors listed in that section, especially the fourth factor, dealing with market effects. (4) Care should be taken to keep abreast of the court determinations and to conform to the court rulings until they are overruled or the statute is amended. (5) As a rule of thumb, it should be considered "fair use" (unless and until the courts rule otherwise) for a teacher, either directly or operating through the library, to put on reserve those materials that could be distributed to individual members of the class consistent with the "fair use" doctrine; a practice that a teacher can engage in directly should be permissible acting through a library as agent. (6) It goes without saying that in doubtful and marginal cases the library should consult with appropriate legal counsel with respect to the validity of the proposed course of conduct.

(5) It is of great importance, during the period of uncertainty and development, that libraries keep full records of what photocopying they engage in; the reasons for doing so; the costs and benefits (both monetary and educational) of what they do as compared to alternative practices; what practices they refrain from engaging in as a result of the copyright law (and, again, the costs and benefits); the specific effect of their practices upon the purchase of or subscription to copyrighted materials; and so on. Such data become highly relevant in connection with possible specific litigation that may result, in shaping court attitudes generally, in their hearing upon the efforts of users and/or owners to amend the law, and in providing assistance to the Register of Copyrights in making the five-year reports required by section 108(i). Such data, important as they are in dealing with the difficult issues that abound in the new law, take on added importance in view of the changes in both practices and effects that are likely to occur as a result of the rapid developments, technological and otherwise, that are occurring in the fields of reprography and communication. ${ }^{21}$

\section{REFERENCES}

1. For the text of these sections see Librarian's Guide to the New Copyright Law (Chicago, American Library Assn., 1977), appendix I.

2. Whether the recipient-lender would be liable is also an interesting question. Section 106(3), giving the copyright owner the exclusive right "to distribute copies ... to the public by ... transfer of ownership, or by lending," might suggest liability. On the other hand, Section 109(a) provides that, "notwithstanding the provisions of Section $106(3)$, the owner of a particular copy ... lawfully made .... is entitled ... to sell or otherwise dispose of the possession of that copy." Any question whether the copy under discussion is "lawfully made" seems to be settled by section 108(a), which states that compliance with the conditions set forth in that section renders the copying a noninfringing act rather than merely providing freedom from liability for infringement

3. The Register of Copyrights, quoting an anonymous source, commented recently as follows with respect to section 108(g): "The first time you read it, it sounds meaningless and the second time you read it, it sounds even more meaningless." Proceedings of the 70th Annual Meeting of the American Association of Law Libraries, LAW LBBR. JRNL 70:453-63 (Nov. 1977)

4. For the text of the guidelines see Librarian's Guide to the New Copyright Law, appendix II, p. 9-11

5. Leon E. Seltzer, "Exceptions and Fair Use in Copyright: The 'Exclusive Rights' Tensions in the New Copyright Act," Copyright Society of the U.S.A. Bulletin 24:215, 237 (1977).

6. U.S., Congress, House, Committee on the Judiciary, Copyright Law Revision, Report No. 94-1476, 94th Cong., 2d sess., Sept. 3, 1976 , p. 74. This comment, taken together with the report's earlier statement (id., p. 66) that "Section 107 is intended to restate the present judicial doctrine of fair use, not to change, narrow, or enlarge it in any way," suggests that the House committee viewed the judicially applied "fair use" doctrine as not limited to use of excerpts in further writings (see reference 5 above). Williams \& Wilkins v. U.S., 487 F.2d 1345 (Ct.Cl. 1973), affirmed by a divided court, 420 U.S. 376 (1975); cf. Wihtol v. Crow, 309 F.2d 777 (8th Cir. 1962).

7. Proceedings, LAw LiBr JRNL. 70:453-63 (Nov. 1977).

8. In many situations a nonprofit educational institution may simply decide to do withoutall the more so, since such institutions usually operate on limited book budgets and must constantly select from a long list of meritorious materials what few items to buy.

9. National Commission on New Technological Uses of Copyrighted Works (CONTU), "Draft Report of the Subcommittee on Photocopying" (15 Mar. 1978), p.70-71

10. Although clearance centers can provide prompt accessibility and reduce red tape, they give no assurance that prices will be reasonable. Two recent examples of high prices demanded by the publisher (both of them nonprofits!) for copies: a 20-page reprint, $\$ 5.00$; copies at $\$ 1.25$ a page. 
11. A quick check of a single copy of each of two publications participating in the Copyright Clearance Center arrangement indicates that, if extrapolated on a year's basis, the fee for photocopying the entire year's issues would be double the year's subscription rate in one case and ten times the rate in the other-and this without any cost to the publisher for printing or mailing. Whether these are typical or atypical, I do not know.

12. This nonbinding effect is applicable to nonparticipating copyright owners just as it is to nonparticipating users.

13. As the Register of Copyrights put it in a recent talk before the American Association of Law Libraries: "They [the guidelines] may be too restrictive in the law school situation.

It does seem to me that this was written with elementary, secondary situations in mind. I am not suggesting that you can go very far beyond this in the law school situation, but it does seem to me ... . that there is a realistic borderline beyond these guidelines that in a law school situation you could probably apply. I am saying that you do not need to regard these as the law of the Meads [sic] and the Persians." Proceedings, LAw Libr. JnnL. 70:453-63 (Nov. 1977).

14. U.S. Congress, House, Report No. 94-1476, p. 72. Emphasis supplied.

15. In her AALL talk, the Register of Copyrights had this to say about reserves, including repeated usage from year to year: “My feeling is that within the ambit of 107 and 108 it can't be stopped, and that up to a point, using photocopies of excerpts and articles is permissible under 108 and 107 combined somehow or other, but when you get to the point where you know [that] what you are doing-you the library or you the professor-is taking money out of the authors' and publishers' royalties, by substituting a photocopy for a sale or purchase, then I think you may be in another dimension." Proceedings, LAW LIBR. JRNL. 70:453-63 (1977).

16. The introduction of the library into the act as the mere copying-and-depositing agent of the teacher, rather than as the initiator of the practice, does not change the picture.

17. U.S., Congress, Senate, Committee on the Judiciary, Copyright Law Revision, Report No. 94-473, 94th Cong., 1st sess., Nov. 20, 1975 , p. 63. The Senate report, again using language taken from the earlier House report, does comment as follows in its discussion of the "nature of the copyrighted work" (p. 64): "A key, though not necessarily determinative, factor in fair use is whether or not the work is available to the potential user."
18. U.S., Congress, House, Report No. 94-1476, p. 67 .

19. For example, if new copies are made for successive uses, as distinguished from repeated usage of copies previously made. See reference 15 above. But repetitious copying may also, as previously noted, cause one to opt in favor of purchasing from an authorized source instead of photocopying. Also one who planned to put a given copy to repeated use, if foreclosed from copying, might be inclined to purchase rather than simply to refrain from using. Cf. reference 8 above.

20. See section $504(\mathrm{c})(2)$ of the act, which reads in part: "The court shall remit statutory damages in any case where an infringer believed and had reasonable grounds for believing that his or her use of the copyrighted work was a fair use under section 107, if the infringer was: (i) an employee or agent of a nonprofit educational institution, library, or archives acting within the scope of his or her employment who, or such institution, library, or archives itself, which infringed by reproducing the work in copies or phonorecords;

21. For example, developments with respect to computers, clearance centers, microfilming, reprint services, etc.

\section{THE PROBLEM} SOLVER:

\section{SERIALS}

Problem: How can anyone involved in serials selection and collection building remain up to date with the changing world of periodicals, journals, newspapers, almanacs, difectories -- serial publications of all kinds?

Solution: Subscribers turn to Serials Review for current reviews, informative and entertaining articles, and indexes to serials. Twelve regular features include Reference Serials, Government Publications, Tools of the Trade, Review Sources, and Serial Review Index. Special features enhance this invaluable publication de. signed to be a major source of advice on which serials and related materials should be on the shelves of your library.

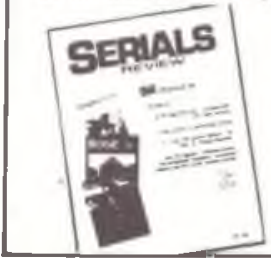

Published quarterly. $\$ 25 / y$. for institu. tions. $\$ 14 / y r$. for individuals.

PIERIAN PRESS 5000 Washtenaw

Ann Arbor, MI 48104 